\section{ALCOHOL INJECTION IN FACIAL NEURALGIA.}

By WILFRED HARRIS, M.D.CAMB., F.R.C.P.LOND., PEYGICIAN FOR NERYOUS DISEASES, STT. MARK'S HOSPITIT AND TO THE HOSPITAL FOR EPITEPSY AND PARALYSIS, ALAIDA VALE.

Although it is more than 18 years since Schloesser introduced his method of injection of the deep foramina of exit of the branches of the trigeminal nerve with strong alcohol for cases of intractable tic douloureux, and although his and other modified methods have attracted considerable attention and have been practised widely throughout the world, it is probably only in the hands of the few that alcohol injection can be relied on to give certain relief in cases of genuine trigeminal neuralgia. Unless the injection method is first carefully studied on different skulls and in the post-mortem room it is hopeless for practitioners to expect any good results by this method, invaluable and certain though it is when properly performed. Schloesser's method of intra-oral introduction of the needle and of injection through the mucous membrane of the buccal cavity and pharyngeal roof, though doubtless efficacious as a method of approach to the foramen rotundum or foramen ovale, is repulsive to the spirit of aseptic surgery, and for that reason I have never attempted injection by his route, but have preferred the external route suggested originally by Levy and Baudouin. This I have modified in various details, and it is as a result of accumulated experience during the past 14 years, in over 600 cases, that I can recommend with the utmost confidence these methods.

Recently in America an account has been published of a method for determining the angle and the line of insertion of the needle to reach the foramen ovale or foramen rotundum respectively by means of an instrument based on certain calculations and skull averages. For my part, I am more than sceptical of the value of such a method, owing to the great variations met with in the size and shape of the heads of one's patients. Such measurements, moreover, take little or no account of the variation in the thickness of the fat and subcutaneous tissues of the cheek, so that a stout face with a broad head may require a needle to be inserted for more than one inch deeper than in a thin face with narrow head, in order to reach the foramen ovale. I deprecate, therefore, any rule-ofthumb method unless it is supplemented by an accurate working knowledge of the anatomy of the zygomatic and spheno-maxillary fossæ and their contents, and modified to meet various cases and anatomical differences.

Such knowledge of the local anatomy of the parts concerned should be so familiar to the operator that he can visualise the depths of the fossæ as he is working, more particularly that he shall recognise with absolute certainty when his needle strikes the spine of the sphenoid or the external pterygoid plate, and that he shall know exactly what his needle will reach when he alters its direction either in front or behind these points. Chronic paroxysmal trigeminal neuralgia in the large majority of cases is limited to the second and third divisions of the nerve. Only in exceptional cases is the first division involved, and then never alone, but in addition to the second division. The distribution of the pain in cases of second division neuralgia is often deceptive, and a large number of pure second division neuralgias are liable to be mistaken for neuralgia affecting the first as well as the second division, on account of the pain being so frequently referred above the eyebrow and across the lower part of the forehead and the front of the temple. It is difficult to explain the reference of the pain in second division neuralgia above the eyebrow on an anatomical basis, though pain extending outside the outer canthus of the eye and in front of the temple is frequent, and is probably a referred neuralgia through the temporo-malar branch. This area of skin is also supplied by the auriculo-temporal branch of the third division, and by the supra-orbital branch of the first division : consequently, this area never becomes anæesthetic as a.result of destruction of either of these divisions alone. The temporo-malar branch arises from the second division far back in the sphenomaxillary fossa soon after the nerve leaves the skull at the foramen rotundum, even before the sensory root to Meckel's ganglion is given off, and I find in practice that it is of no consequence whether the needle strikes the nerve in front or behind these branches. This fact is in harmony with my view of the pathology of chronic trigeminal neuralgia, that it is. due to septic neuritis of nerve filaments of the second or third divisions in the upper or lower jaw respectively, and originated by septic infection from carious teeth, pyorrhœea, antral abscess, and other causes of septic osteitis. Thus, neuralgias of the temporomalar region, auriculo-temporal, palatal, or lingual branches, are to be looked upon as referred neuralgias, and not primary, and are really due to a primary focus in the upper or lower jaw respectively. Thus, in some trigeminal neuralgias affecting the third division only the pain may be most intense in the tongue, yet division of the lingual nerve is a most unsatisfactory treatment of the complaint, and it is not until the inferior dental branch is also anæsthetised that immunity from pain is secured.

\section{Second Division.}

To understand and to practise successfully injection of the second division at the foramen rotundum close study of the route should be first made with an articulated skull, with the lower jaw fixed in position. A long needle (three inches or more) or a hat pin should be passed in front of the coronoid process, and under the malar bone, upwards and backwards at an angle of about $45^{\circ}$. The needle will thus be found to pass behind the backward bulge of the antrum of Highmore, and in front of the anterior border of the external pterygoid plate, through the narrow chink between these two bones known as the pterygo-maxillary fissure, the needle thus entering the spheno-maxillary fossa on its way to the foramen rotundum, which lies about a quarter of an inch deeper than the anterior border of the external pterygoid plate.

The needle can in many skulls be made to rest against the inner lip of the foramen rotundum, and when held in this position, with the shaft of the needle close to the malar bone and anterior border of the coronoid process, it will be seen that the angle of the direction of the needle is nearly $45^{\circ}$ upwards from the horizontal, and it will also be seen that the needle is directed towards the point where the ascending orbital process of the malar bone rises steeply from the zygoma. This point can always be felt with the finger and marked with a skin writing pencil on the patient: the anterior border of the coronoid process can also always be made out by pressing the finger under the malar bone and backward to the coronoid process. This point should also be marked with the pencil and a straight line drawn downwards across the cheek joining the two points that have been marked, and it will be seen that a plane roughly at right angles to the cheek through this line will pass through the foramen rotundum, so that a needle entering the cheek through the lower point and directed upwards and backwards in this plane at an angle of just under $45^{\circ}$ will pierce the superior maxillary nerve at the foramen rotundum. Occasionally it will be found that the backward bulge of the antrum is so great, and the coronoid process comes so far forward, that the needle cannot be made to pass through the pterygo-maxillary fissure, and it will then impinge either on the superior maxilla or the external pterygoid plate. Indeed, in the anthropoid skulls, such as the gorilla or chimpanzee, this is the normal condition. An alternative route of approach therefore for injection of the second division is necessary. This can be done by sinking the needle through the cheek behind the coronoid process 
instead of in front of it, and the most satisfactory point for entrance of the needle is precisely that , which I use for injection of the third division at the foramen ovale, to be presently described. Instead, however, of passing the needle slightly backwards, so as to reach the foramen ovale behind the external pterygoid plate, it is directed forwards and slightly upwards, the upward angle being about $15^{\circ}$, and the forward angle varying from $15^{\circ}$ to as much as $45^{\circ}$. The necessary forward angle must be determined by trial, the needle being sunk to reach the external pterygoid plate as a landmark, this depth being usually $1 \frac{7}{8}$ to 2 inches. When this is felt the needle must be manipulated by slightly withdrawing and again advancing the needle, changing its direction gradually forward until its point is felt to slip over the anterior border of the external pterygoid plate. The depth reached on the needle at this point should be noticed, the depth of the external pterygoid plate being a useful landmark, as the foramen rotundum lies almost exactly $\frac{1}{4}$ inch deeper still. 'This route of approach causes the needle to strike the superior maxillary nerve rather more anteriorly than by the method previously described in front of the coronoid process, and the point of the needle cannot be made to engage in the foramen rotundum; yet in spite of this in the majority of cases where I have used this route for injection I have obtained anæsthesia of the palate as well as of the cheek and upper jaw, showing that the nerve was hit behind Meckel's ganglion. If the operation is done under local novocain anæsthesia only, or with additional partial morphine anæsthesia, the patient will generally indicate when the nerve is struck by flinching and by complaining of an electric thrill sensation in the side of the nose and upper lip, or, as I have frequently noticed, of a sensation of spray upon the cheek, this more particularly when novocain is injected into the nerve. I use sterilised 2 per cent. solution of novocain when the patient gives this indication, injecting three or four drops, and if the nerve has been correctly punctured anæsthesia of the upper lip can be demonstrated by testing with a pin within 15 or 20 seconds. Keeping the needle in the exact position and quietly changing the syringe, 90 per cent. alcohol is now injected, two or three drops at a time, waiting some half minute or more after each push of the piston, and noting the increasing density of the anæesthesia on the upper lip and nasal septum, until neither pinpoint nor even pressure on the jaw is perceptible. The patient will very likely notice a sensation of swelling of the upper lip and cheek, and of the roof of the mouth on that side, and will be surprised to realise afterwards on looking in a mirror how little change there is. Three-quarters to 1 c.cm. of alcohol will be sufficient to produce this effect, but it is best not to inject any alcohol until anæsthesia to novocain is demonstrable.

While searching with the needle for the second division of the nerve a complication not always possible to avoid is puncture of the internal maxillary vessels, as these pass into the spheno-maxillary fossa by more or less the same route as the needle is taking. With increasing experience I find that this occurs more and more rarely, and it is less liable to occur when the route behind the coronoid process is chosen. In any case care should be taken to manipulate the needle delicately and to avoid lateral movements, the direction of the needle being changed by partially withdrawing it first. The stouter the needle that is used the more danger there is of hæmatoma. Should this occur the needle should be instantly withdrawn and firm pressure applied for several minutes before resuming operations, the needle being meanwhile carefully syringed out with boiled water, as if any blood is left in the calibre of the needle a firm coagulum blocking the needle will occur as soon as alcohol is used. This is, indeed, a trap for the unwary, for unless the piston fits the barrel of the syringe absolutely accurately, which is rarely the case, subsequent injection of novocain and alcohol may be attempted after the nerve has actually been struck by the needle, and yet no anxsthesia results owing to the contents of the syringe leaking back past the piston instead of passing on through the calibre of the needle. Much disappointment may thus arise, and much time may be wasted in searching for the nerve, when a blocked needle is the whole cause of the difficulty. As soon as dense anæesthesia of the upper lip both to pin and pressure and of the nasal septum has been produced, total cessation of the neuralgic spasms is absolutely certain, and the patient can safely be guaranteed a period of many months at least of freedom from neuralgia. Often, indeed, the immunity lasts for years.

Another possible route of approach to the foramen rotundum is from the front along the floor of the orbit, the needle being passed in near the outer angle of the orbit, slightly inwards and backwards along the direction of the infra-orbital canal The orbital route of approach has also been recommended recently by an American author for injection of the Gasserian ganglion, by passing the needle through the sphenoidal fissure. I have, however, no experience of it.

\section{Infra-orbital Injection.}

In certain cases of second division neuralgia, especially when the pain may be started by a light touch of the upper lip and side of the nose, injection of the infraorbital branch alone may be sufficient; I have seen on several occasions total cessation of the neuralgia from such infra-orbital injection persisting as long as four or even five years. This injection is comparatively easy to perform, and though a shorter needle may be used than that required for the deeper foramina I usually use the same. First puncturing the skin of the cheek with a hypodermic needle attached to a syringe with 2 per cent. sterile novocain solution, at a point about $\frac{3}{4}$ inch outside and above the lower border of the ala nasi, the larger needle is then inserted and directed upwards and slightly outwards so as to enter the infra-orbital foramen, the left forefinger being kept firmly pressed on the lower orbital margin in order to feel the needle should it slip over this ridge towards the orbit instead of under it into the infra-orbital foramen. As soon as the nerve is punctured the patient is liable to feel a thrilling sensation in the upper lip and nose, and injection firstly with novocain will anæsthetise the upper lip and side of nasal septum. As soon as this is recognised by testing, the alcohol syringe is substituted for the novocain, and destruction of the nerve completed with little or no pain. Often the needle can be pushed some $\frac{1}{4}$ inch or $\frac{1}{2}$ inch along the infra-orbital canal, and the anterior dental branches may then also be anæsthetised, so that the premaxilla may be less sensitive to pressure, but otherwise infra-orbital injection does not abolish sensation to firm pressure upon the cheek although sensation to touch and pin is absolutely lost. The palate, of course, too, is not affected by this injection.

\section{Third Division.}

Although the inferior dental is the main source of neuralgia in this branch of the nerve I never attempt to inject it alone, but invariably attack the third division at its exit from the foramen ovale at the base of the skull. As a result it is true that injection of the foramen ovale anæsthetises the auriculotemporal and lingual nerves as well as the inferior dental, and in addition will cause motor paresis of the masticatory muscles on that side; yet in my opinion the certainty of the injection of the foramen ovale more than compensates for the added anæsthesia and motor weakness, and the period of immunity from neuralgia when the foramen ovale is injected is probably much longer than if the inferior dental nerve alone is attacked. Thus, a female patient had the inferior dental nerve divided by operation, giving her immunity from neuralgia for two years only. After suffering with the recurrent neuralgia for another 12 years, I injected her third division with alcohol at the foramen ovale, and she has now been 
completely free of the pain for the past 13 years. Injection of the inferior dental nerve can only be done from within the mouth, where it enters the inferior dental canal in the mandible. Guarded at this point by the spine of Spix on its inner side, it must be extremely difficult, if not impossible, actually to puncture the nerve. It is true that injection of a quantity of novocain solution at this point will gradually infiltrate the nerve and produce anæsthesia of its distribution after the lapse of about 20 minutes, but alcohol, being a tissue fixative, is less likely to infiltrate the nerve, and unless injected directly into the nerve substance is likely to prove a failure. Injection of the terminal cutaneous branch of the inferior dental nerve at its exit from the menta foramen is practically valueless, and I have not used it for many years. It is possible thus to anæsthetise the chin and lower lip, and a slight mitigation only of the severity of the paroxysms may occasionally result.

For understanding the route of approach to the foramen ovale through the side of the cheek it is best again to take the articulated skull, with the lower jaw in position, and to pass a needle through the sigmoid notch in the mandible almost straight inwards and horizontally to the foramen ovale, which can be seen as an egg-shaped slit in the under-surface of the great wing of the sphenoid, and directed downwards, outwards, and slightly forwards. The depth of this foramen from the surface of the skin will vary from $1 \frac{5}{8}$ in. in a lean face with narrow head to as much as $2 \frac{5}{8}$ in. or even more in a large square head with thick subcutaneous tissues. Looking again at the articulated skull, a tubercle will be seen on the under-surface of the zygoma and in front of the glenoid cavity. A plane drawn at right angles to the side of the head through the middle of this tubercle will pass through the foramen ovale. This tubercle cannot well be felt through the skin even in a thin subject, consequently I prefer to mark the middle of this tubercle by measurement from a definite fixed point. With a skin writing pencil I mark out the undersurface of the zygoma, which always can be felt. I then measure an inch forwards from the middle of the external auditory meatus, marking this point on the under-surface of the zygoma. This point corresponds as nearly as can be with the middle of the tubercle. Next I draw a line from the incisura notch of the ear forwards towards the lower border of the ala nasi. This line in the average skull corresponds with the bottom of the sigmoid notch in the mandible, which is the lowest point behind the coronoid process at which the needle can be passed into the zygomatic fossa.

A vertical line is then drawn downwards through the point marking the middle of the tubercle on the zygoma, and this line usually crosses the line drawn forwards from the incisura notch at a right angle. In some skulls, however, the auditory meatus is set more above the zygoma than usual, so that the incisura-ala-nasi line slopes downwards, and the vertical line will then not cross it at a right angle. A plane drawn perpendicularly to the zygoma through the vertical line already described will pass through the foramen ovale. Consequently, a needle might be thrust through the cheek at the point where the vertical line crosses the incisura-ala-nasi line, and, passed directly inwards and very slightly upwards, should hit the foramen ovale. However, as the foramen ovale looks rather forward, and the spine of the sphenoid slopes rather steeply outwards as well as backwards from the foramen ovale to join the temporal bone, it will be seen in the articulated skull that a better line of approach to the foramen ovale will be in front from a point somewhat in front of that already described. Consequently, I draw on the skin another vertical line parallel to that already described and a quarter of an inch in front of it, and at the point where this line intersects the incisura-ala-nasi line I insert my needle; its direction now must not be quite straight inwards but very slightly backwards, in order to hit the plane drawn through the posterior vertical line at the correct depth.

As this depth varies with different sized and shaped heads, the line of direction of the needle will vary from $15^{\circ}$ backwards to practically straight inwards, and, as I have already said, the depth at which the nerve will be struck at the foramen will be liable to vary by as much as an inch or even more. No vessel of importance is likely to be wounded by this route of injection. The internal maxillary vessels almost invariably turn forwards at a level below the bottom of the sigmoid notch in the mandible, and are consequently safe. Behind the foramen ovale the middle meningeal artery enters the skull at the foramen spinosum, and this vessel may easily be wounded, but it is a small vessel, and outside the skull is of no practical importance. Another much more important structure to avoid is the Eustachian tube, which may be struck by the needle usually at a point slightly posterior to and deeper than the foramen ovale. If general anesthesia is not employed the patient will generally signify this occurrence by complaining of pain deep within the ear. No injection should ever then be made either of novocain or alcohol, because of the danger of producing middle-ear deafness or even abscess of the middle ear.

As soon as complaint of pain in the ear is mentioned by the patient the needle should be partially withdrawn, and redirected slightly forward. When the nerve is struck by the needle the patient may complain of a thrill or twinge in the chin or tongue, but in probably half the cases no pain may be referred. peripherally but may be complained of locally and deep. In such a case, so long as the pain is not complained of deep within the ear, an injection of a few drops of novocain should be made, and if the needle has really punctured the nerve anasthesia will appear definitely within 20 seconds. If no anæsthesia appears the needle should be pushed an eighth of an inch further inwards, as its point may have just reached the nerve but yet the whole of the needle is outside the nerve, and consequently the novocain does not produce immediate anæsthesia. As soon as definite anæsthesia appears alcohol should be injected, two or three drops at a time, until about a cubic centimetre has been used, before which time total anæsthesia should have been produced. Occasionally there is difficulty in finding the nerve, when it will be a good plan to direct the needle slightly forward in order to hit the external pterygoid plate. This landmark will be a useful indication of the correct depth necessary, as the foramen lies immediately behind the upper posterior border of the plate; the needle should then be slowly worked backwards until its point, so to speak, falls off the back edge of the plate, when the point should be slightly raised by depressing the mount and the needle pressed slightly inwards.

\section{Injection of the Gasserian Ganglion.}

As the needle point thus lies within the nerve resting on the inner lip of the foramen ovale, it will often be noticed that after the third division has become totally anæsthetic, as the result of the injection of five or more drops of alcohol, pain is complained of round the eye and perhaps the forehead with each succeeding push of the piston, and rapidly anæsthesia may develop over the whole of the first division, including forehead, eyeball, and cornea; while the second division, as shown by testing the upper lip and nasal septum, is only slightly anæsthetic. This is probably to be accounted for by the alcohol permeating through the root of the third division within the sheath of the Gasserian ganglion, and working its way round into its inner margin. When this occurs I usually wait a few minutes without injecting any more alcohol, and almost invariably after the lapse of five or ten minutes, or even lẻss, sensation rapidly returns to the eyeball and forehead, and within two or three minutes sensation to pinprick and light touch may become perfectly normal 
again. This rapid return of sensation over the first division, while the third division remains completely anæsthetic as before, is no doubt to be explainerl by the alcohol causing a condition of nerve shock in the cells of the inner portion of the ganglion without destroying its substance. If now it is desired to destroy the ganglion, instead of continuing to push more and more alcohol as before, it is advisable to push the needle another one-eighth to a quarter of an inch with a screwing motion through the foramen ovale into the substance of the ganglion. Then very cautiously a drop or two of alcohol is again injected, and if the same resistance to the push of the piston as before is again experienced, it may be assumed that the point of the needle is still within nervous tissue. Drop by drop more alcohol is injected at intervals of about half a minute, while the sensation on the second and first divisions is carefully tested, and usually it will be noticed that now the second division becomes totally anæsthetic before the first division. Perhaps the ideal result to achieve is total anæsthesia of the second and third divisions, with not quite total anæsthesia of the first division, so that pressure upon the forehead and eyeball is at once perceived. When this is the case there is no danger of subsequent keratitis.

Occasionally, after pushing the needle upwards through the foramen ovale, it will be found that the piston experiences no resistance upon injecting a drop or two of fluid, and immediately the patient complains of frontal or even occipital pain. This is due to the point of the needle having passed through the ganglion into the cave of Meckel, and the needle must be at once partially withdrawn and an attempt made to reinsert it slightly further back in the foramen ovale.

\section{First Division.}

This division is comparatively rarely affected in trigeminal neuralgia except reflexly through the second division. That is to say, it is quite uncommon for the neuralgic pain to persist from eyebrow to vertex after the second division has been properly anæsthetised at the foramen rotundum. Occasionally, however, neuralgic spasms do persist over the supraorbital division of the nerve, though I have never known it affect any other portion of the first division. The supramorbital nerve usually passes through a grove, or even bony foramen in the supra-orbital ridge, at a distance of about one inch from the middle line. The nerve can even be injected at this point by a hypodermic needle fitted on to a small syringe.

\section{Injection under General Ancesthesia.}

Injection of the various branches or of the ganglion may be done either after using novocain locally, or under scopolamine-morphine anæsthesia, with novocain locally; or a general anæsthetic may be used, either gas and oxygen, or light chloroform anæsthesia. Scopolamine-morphine anæsthesia is rather apt to make patients uncertain in their answers, and therefore may be misleading. Under either gas and oxygen or chloroform alone the injection cannot be properly guided by the patient's sensations, and the finding of the foramen ovale or foramen rotundum must be trusted somewhat to chance. After inserting the needle in the average direction and to an average depth under light chloroform or gas anæsthesia often a peculiar sharp flinch of the patient may indicate that the nerve has been struck properly. Giving then a few drops of novocain solution I stop the anæsthetic at once and allow the patient to recover, testing the area of distribution of the nerve on the skin, such as the lower lip or upper lip respectively. Presently, as the patient recovers, he will flinch when the pin test is used on the unaffected side; then, if he does not flinch when the pin is tested on the corresponding lip of the affected side, this indicates that the nerve has been properly punctured, and now alcohol should be injected drop by drop as already described. If, however, the patient flinches equally when either side is tested with the pin, then a few more whilts of chloroform must be given, and the needle readjusted in the search for the nerve, and the process repeated until the required anasthesia is produced. In this way I have frequently injected both the second and third division under light chloroform anasthesia through one puncture behind the coronoid process.

\section{Results.}

Strong alcohol, being a tissue fixative, coagulates the albuminous elements of the nerve fibres and dissolves the fatty sheath of Schwan. Degeneration downwards of the nerve then results from the point of injection, and the process has been termed neurolysis. Regeneration of the nerve fibre occurs in the ordinary course, and may be more or less complete in two years. In my experience sensation never returns so fully in the third division as after injection of the second division. Freedom from the neuralgia may practically be guaranteed for 12 months, if the nerve has been properly hit, and in the majority of my cases th immunity from pain has been much longer, ranging up to 13 years in the case of third division neuralgia already referred to. Four and five years is a quite common period for the immunity to last in my experience. In many scores of cases in which I have injected the Gasserian ganglion there seems no reason why, in those with total anæsthesia, the cure may not be as permanent as in cases of complete gasserectomy or resection of the sensory root behind the ganglion, though the injection operation is infinitely less severe, and is practically free from risk when done by an expert, though, I repeat, it is not an operation to be attempted until considerable experience of the method has been gained.

\section{VENOUS ANGEIOMA OF THE CEREBRAL CORTEX,}

WITH REPORT OF A CASE.

\section{BY CECIL WORSTER-DROUGHT, M.A.,} M.D. CaMb., M.R.C.P. LoND.,

ASSISTANT PHYSICIAN, WEST-END HOSPITAX FOR DISEASES OF THE NERYOUS SYBTEM ; LECTLRER IN NEUROLOGY, BETHLEM ROYAL HOSPITAL, ETC. ;

$$
\text { AND }
$$

Sir CHARLES A. BALLANCE, K.C.M.G., F.R.C.S. ENG.,

VICE-PRESIDENT, ROYAL COLLEGE OF SURGEONS, ETC.

ANgeiomata of the cerebral cortex are among the rarest of brain tumours. Most of the cases recorded have been examples of plexiform arterial angeiomata. occurring in connexion with the cerebral arteries. Thus, Drysdale ${ }^{1}$ reports two cases of arterial angeioma on the surface of the anterior lobe of the cerebrum connected with the anterior and middle cerebral arteries; D'Arcy Power ${ }^{2}$ records a similar condition situated over the angular gyrus, and further cases are reported by Kalisher, Emanuel, BergmannOppenheim, ${ }^{3}$ and Simmonds. ${ }^{4}$ A few cases of circumscribed cavernous angeioma have also been described notably by Bruns, Oliver, Stuppler, and Bielschowsky. Cerebral angeiomata consisting entirely of veins, however, are apparently even rarer than either of the above-mentioned conditions ; consequently, the following case of extensive venous angeioma of the right cerebral cortex, associated witb mild hemiplegia and epileptic attacks of the Jack sonian type, is of considerable interest. Curiously enough, a somewhat similar example of venous. angeioma in a younger subject, but consisting of vessels of smaller calibre, occurred in the same hospital a few weeks earlier, and has been recorded by Harry Campbell and C. A. Ballance. ${ }^{5}$ D. M. Greig ${ }^{6}$ also has recently reported a case associated with hemiplegia, epilepsy, and adenoma sebaceum, in a youth aged 18. 